\title{
Field Notes for Future Petropractices: Refiguring Oil and/as Media
}

\author{
Elia Vargas ${ }^{\text {a }}$ \\ Keywords: oil, elemental media, media art, petrocultures, agential realism, art and science, oil mysticism \\ https://doi.org/10.1525/001c.18931
}

The seemingly prosaic question "What is oil?" opens up a mystifying world of new conceptual frameworks, ethics, and material circumstances. What does it mean to think with oil beyond the practices of representation that enact its contemporary form?

Between 2015 and 2018, my ongoing critical and creative oil research led to a series of crude oil media artworks, which illuminate, materialize, and reexamine basic assumptions of oil. Thinking with the diffractive methods of feminist science studies scholar Karen Barad, "Field Notes for Future Petropractices" addresses the artworks Oil Ontology (2017), Crude Illumination (2015), and Oil rituals for the future \#6 (2018). Each of these uses the enigmatic product Crudoleum, 100\% Pennsylvania Crude Oil Scalp Treatment, to enact the openended performativity of oil.

My critical and creative practice, in which practices of making reciprocally determine and blur with practices of thinking, examines the early American oil industry and its entanglements with mysticism. This period matters because it is the commonly accepted historical origination of crude oil as a global energy commodity. As new energy regimes and new critiques of the Anthropocene emerge, it is crucial to continue examining how the ontological status of oil as a fossil fuel persists. Why is it taken for granted that oil —an earth material that exceeds anthropocentric categorization - is represented exclusively as fuel?

The idea that beings exist as individuals with inherent attributes, anterior to their representation, is a metaphysical presupposition that underlies the belief in political, linguistic, and epistemological forms of representationalism. Or to put the point the other way around, representationalism is the belief in the ontological distinction between representations and that which they purport to represent; in particular, that which is represented is held to be independent of all practices of representing. (Barad 2007, 46)

Oil does something profoundly different than ideology. It restructures our relationships and capacities to perceive. Oil produces our daily lives, our daily selves, our daily communities

\footnotetext{
a Elia Vargas is an Oakland, California-based artist and scholar. He works across multiple mediums, ranging from video and sound to writing and performance, focused on naturecultural media practices. He is a Ph.D. candidate in Film and Digital Media at the University of California, Santa Cruz and is the co-founder and co-curator of the Living Room Light Exchange, a monthly salon on critical, intersectional perspectives of art and technology. He collaborates widely with artists, musicians, and institutions, and has worked at internationally acclaimed interactive design studios. As an educator and organizer, he is a steward for self-determination through critical and creative practice. His current work considers the cultural, philosophical, and techno-scientific conditions of the early American oil industry and argues for refiguring crude oil as media to decenter anthropocentric representations of nature.
} 
and everything else in a primary way. It has a definitive role in forming understanding of self and relation to the world and others. (Bloom 2015, 23)

The seemingly prosaic question "What is oil?" opens up a mystifying world of new conceptual frameworks, ethics, and material circumstances. Oil is a resource commodity; oil is technoscientific; oil is political; oil is an earthly substance. But what does it mean to think oil beyond the practices of representation that enact its contemporary form? Amidst a world that fundamentally underestimates the extent that it is produced by and through oil, taking stock of oil's constitution, its history, and its potentiality is surprisingly absent. This is true, despite a growing domain of critical, creative, and popular examinations of oil. Although the energy humanities, and specifically the rise of scholarship on "petrocultures," have expanded critical examination of what the contemporary moment calls oil, there are still many unanswered earthly matters at stake. Between 2015 and 2018, my ongoing critical and creative oil research led to a series of crude oil media artworks, which illuminate, materialize, and reexamine basic assumptions of oil. Thinking with the diffractive methods of feminist science studies scholar Karen Barad, I will discuss my artworks Oil Ontology (2017), Crude Illumination (2015), and Oil rituals for the future \#6 (2018); others make brief appearances. Each of these uses the enigmatic product Crudoleum, 100\% Pennsylvania Crude Oil Scalp Treatment, to enact the open-ended performativity of oil (figure 1).

This series of artworks is a component of a broader and ongoing project to refigure crude oil as media through a posthumanist analysis of the early American oil industry. The period matters because it is the commonly accepted historical origination (however suspect such grand narratives may be) of crude oil as a global commodity. The overarching project asserts that oil is media by developing an agential realist media theory. Agential realism challenges implicit assumptions in the representations of objects and agents that have solidified as essential and universal in material and discursive conditions of the world. Applying this thinking to oil, and specifically to the early American oil industry, opens new ways of understanding ongoing human-oil relations with/ in a world that has always already been more than human.

In $A$ Geology of Media, media theorist Jussi Parikka develops a notion of media materiality that I adopt to bring together oil and agential realism. "Media materialism," Parikka says, "refers to the necessity to analyze media technologies as something that are irreducible to what we think of them or even how we use them. It has come to refer to technology as an active agent in the ontological and epistemological sense. In other words, media structure how things are in the world and how things are known in the world" (Parikka 2015, 1). Parikka's attention to what he calls medianatures in the materialization of digital culture links together the naturecultural work-the entangled 


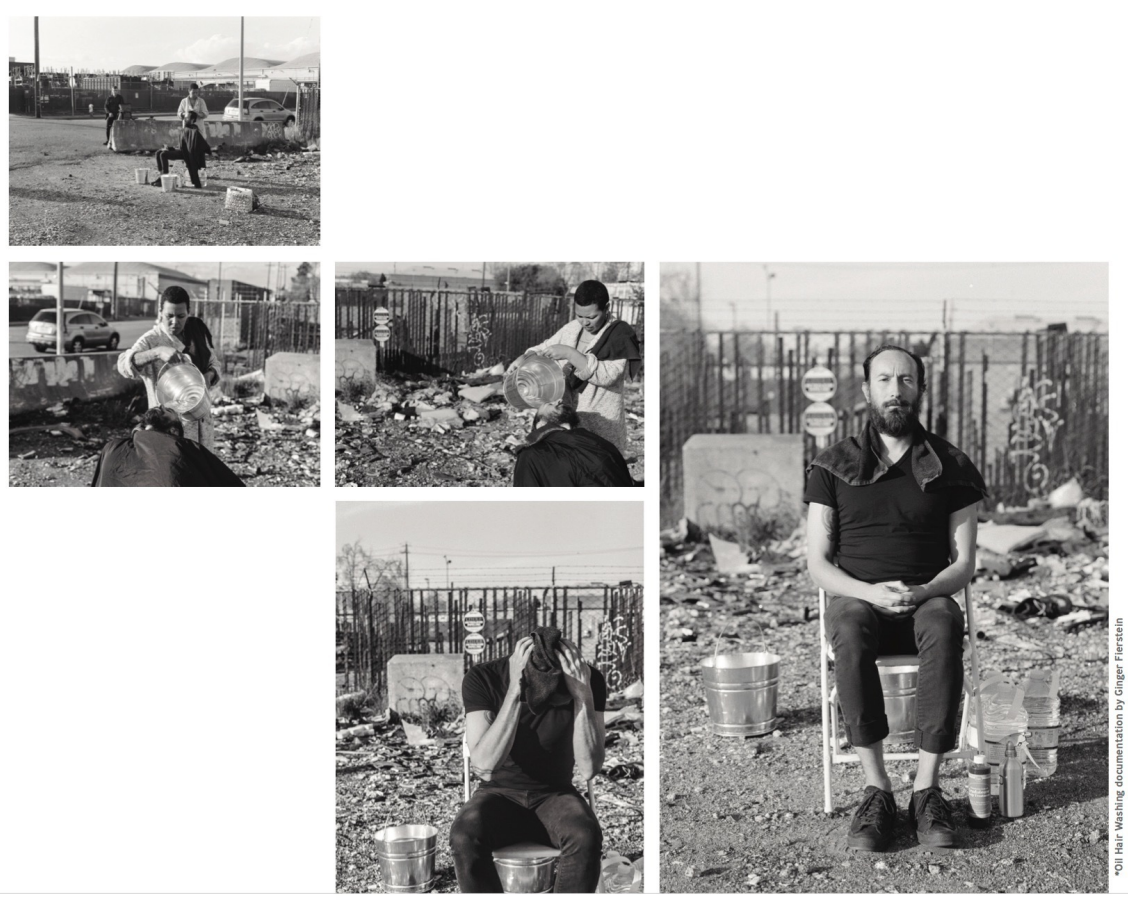

Figure 1: Crudoleum hair washing on March 25, 2017, at historic Station B, site of the first crude oil production in Oakland, California, in 1902. Shimeko Franklin washes Elia Vargas's hair with Crudoleum as part of 100 Days Action, 2017.

Image from self-published speculative exhibition catalogue of Vargas's solo exhibition, Lubricated Substrates at B4BEL4B gallery, Oakland, California. Catalogue designed by Sming Sming Books. Photos: Ginger Fierstein. Reproduced with permission.

inseparability of nature and culture-of feminist science studies philosophers including Barad and Donna Haraway (Haraway 2003). The naturecultures of agential realism can take Parikka's argument further and illustrate that nothing-like oil, or pipelines, or kerosene-has specific attributes ontologically distinct from the conditions in which they are enacted, even as they play profound roles in the ongoing differentiation of the world.

Although this research includes an expanded agential realist media theory, fieldwork at Oil Creek State Park in Pennsylvania (the site of the first commercial American oil well, Drake Oil Well), archival research, and other site-specific methods, my focus here is on the conditions surrounding the artworks. They will be discussed over the following four sections. But before the artworks are addressed, the first section is reserved for an introduction to agential realism and why it is an important framework for this work. The remainder of the introduction explicates why such a project is necessary and sets up the kind of interdisciplinary engagement this is: the critical and creative components work together to shine light on other materializations of oil.

There is a lack of imagination in popular culture, and much scholarship to boot, in conceptualizing oil as merely a fossil fuel-a naturalized commodity available for human extraction. Notably, historical conceptions of crude oil are vast, including long periods that normalized oil as a substance unrelated to fuel, in forms such as medicine, chewing gum, and polymers. The first industrial 
use of oil was kerosene (as fuel for artificial domestic light), developed in the late 1840 s and popularized shortly thereafter. Oil and illumination, in fact, are inextricably linked. Oil is, physically, latent solar energy stored in ancient bodies.

Illumination-including its dynamic ongoing materialization-is a crucial component of the artworks at hand. The artworks draw attention to oil as an indeterminate medium that metamorphoses the representational axes of time and space (and matter) simultaneously toward a geologic deep time that exceeds an industrialized sense of time and also toward the social, temporal, and spatial transformations that industrial oil infrastructure has enacted. In defense of critical engagement with oil — and systems of perceiving and knowing - artistic practice lends new perspectives and new methods for how oil might be perceived, such as practices of touching, smelling, and other forms of ongoing embodiment.

Given the outsize role that oil has played in making the contemporary world-creating democracy (Mitchell 2011), defining capital (Malm 2016), shaping the everyday (Huber 2013), mediating culture (LeMenager 2014), and determining infrastructural and discursive scientific practices (Bowker 1994), to name just a few-a specific and important question has gone underexamined. As new energy regimes and new critiques of the Anthropocene emerge, why does the predominant ontological status of oil as a fossil fuel persist? Why is it taken for granted that oil-a material of the earth that exceeds anthropocentric categorization-should be represented distinctly as fuel? Articulated through agential realism, this is an important posthumanist question that the primarily (and perhaps unfairly generalized) Marxist and literary studies work of the petrocultures field does not address.

The question matters. Moving beyond the current fossil fuel impasse-what Gregory C. Unruh calls "the carbon lock-in," the self-perpetuating infrastructure, technology, and policy of fossil fuels (Malm 2016, 7) —was a major theme of the 2018 Petrocultures Conference. ${ }^{1}$ However, as long as a solution to the impasse does not address the similarly self-entitled Western industrial right to define earth energies as subjects of human activity, this otherwise positive shift perpetuates anthropocentric representations of life, regardless of the energy sources that replace fossil fuel. There are increasingly more engagements with this posthumanist idea, such as Fuel: A Speculative Dictionary (Pinkus 2016), though not yet enough to meaningfully expand the popular Western humanist conception of oil as a useful substance for humans with economically productive and environmentally destructive potential.

\footnotetext{
1 The Petrocultures Conference is an international and multi-disciplinary conference on Oil Cultures and Energy Humanities organized by the Petrocultures Research Group at the University of Alberta, co-directed by Imre Szeman and Sheena Wilson. The Petrocultures Conference 2018: "Transitions" took place between August 29 and September 1, 2018 at University of Glasgow, in Glasgow, Scotland. For more information see the conference website: https://petrocultures2018.wixsite.com/transition or the Petrocultures Research Group website https://www.petrocultures.com/.
} 
Heidi C. M. Scott's Fuel: An Ecocritical History tackles the subject by arguing for a different energy ontology. "With renewable energies like solar and wind coming online," she says, "in time we will see the fossil-fueled load redistributed to these renewables, but the paradigm of a fossil-fueled ontology remains largely unchallenged" (Scott 2018, epub 51). She continues, "Anthropocene scholars have established how the eco-cultural condition in which we conduct our lives is marked by the wholesale conversion of nature into materials that energize human economies" (Scott 2018, epub 51). Her argument raises the specter that oil-as understood throughout industrialization-is a manufactured technology produced through technical, social, and natural practices to be a human tool. Cara New Daggett's The Birth of Energy, published while I wrote this essay, tackles the entwined naturecultural conception of work and energy (Daggett 2019). Daggett demonstrates that the very science of energy-thermodynamics-cannot be extracted from the material and discursive conditions amid which it came into existence in the 1840 s.

There is a need for more work that refigures oil beyond traditional humanist notions of nature and culture, human and nonhuman, subject and object, which produce the metaphysics of individualism that Barad critiques. It is through these fabricated dualities that the industrial-scientific conception of oil is cemented into place. Returning to the question "What is oil?," my practice argues for refiguring the onto-epistemological status of oil as media. This shift means evaluating the conditions of contemporary oil practices without presuming underlying universal characteristics of what constitutes nature and culture, human and nonhuman, subjects and objects, time and space. To assume any of these is to insert social representations with/in a substance that does not depend on them to exist.

Because oil is one of the preeminent substances of contemporary life, engaging the material conditions of its existence as a fossil fuel carries stakes that reach beyond oil itself. Brett Bloom calls this petro-subjectivity (Bloom 2015). Barad offers another route. The theory of agential realism proposes a materialdiscursive philosophy: that there is no ontological distinction between objects and agencies of observation. Instead, objects and agencies intra-actively coconstitute matter's ongoing differentiation of the world. Agential realism serves as my foundation to rethink oil's specific ongoing materialization and the ethics of its mattering.

\section{Oil. Art. Agential Realism.}

Before discussing the artworks, it is necessary to briefly introduce agential realism. Barad developed the theory of agential realism in response to the philosophy-physics of founding quantum physicist Niels Bohr, who demonstrated that light could be both a particle and a wave. Agential realism challenges the conception that any particular thing exists with inherent attributes separate from the conditions that constitute the possibility of those 
attributes. Nature, culture, society, technology, agency, objects, subjects, time, space, and a litany of power relations including colonialism, sexism, and xenophobia are constituents of specific relations in their becoming, not preexisting categories. Diffractively reading oil means understanding how oil is enacted in its material-discursive becoming. I want to stress the specifics of language here. Agential realism offers a new vocabulary for thinking beyond the practices of representation that assume preexisting, discrete categories such as those of space and time, subject and object. However, agential realism is not about words (discourse). It is a material-discursive approach to understanding matter's ongoing differentiation/differentiating of the world. It is difficult to talk about because words are representations that often unwittingly reinforce the dualisms that agential realism challenges. Such are the trappings of logocentrism and its emphasis on signification, which critical praxis helps to ameliorate. Any attempt at a paraphrased shortcut will inevitably fall short because it takes work to rework the knowledge practices that agential realism calls into question.

To more deeply engage with this work, here is a brief summary of important concepts in agential realism that will help to build this new vocabulary. For Barad, the term "apparatus" has important technical significance, meaning "the material conditions of possibility and impossibility of mattering; they enact what matters and what is excluded from mattering" (Barad 2007, 148). Parikka suggests this concept provides grounds for a new media theory (Parikka 2009). Apparatuses are material-discursive becomings; they are specific intraactively enacted instruments, agents, networks, and concepts. "Intra-action," a foundational concept of agential realism, is the ontological inseparability of determinate entities (Barad 2007, 128). Phenomena, Barad argues, are the intra-action (not interaction) of objects and agencies; matter and meaning intra-actively co-constitute each other. Discursive practices are not merely words or speech acts but rather "are specific material (re)configurings of the world through which the determination of boundaries, properties, and meaning is differentially enacted...” (Barad 2007, 148). Therefore, to summarize, "material apparatuses produce material phenomena through specific causal intra-actions, where 'material' is always already materialdiscursive..." (Barad 2007, 153). Things, beings, and meanings are not essential, independent, determinate entities.

Through intra-action, Barad proposes a posthumanist performative approach. 'Posthumanism doesn't presume the separateness of any-'thing,' let alone the alleged spatial, ontological, and epistemological distinction that sets humans apart" (Barad 2007, 136). Far from suggesting that the human doesn't matter or that posthumanism denies the human, this account argues that one cannot start from a position that assumes the human. The social, cultural, technological, and natural conditions that participate in co-constituting the human are not neutral, essential, or apolitical, and are themselves intra-actively co-constituted. Representationalism relies on the unexamined notion that 
these categories exist prior to the instruments, methods, and practices that produce those representations. "The move," Barad says, "toward performative alternatives to representationalism shifts the focus from questions of correspondence between descriptions and reality (e.g., do they mirror nature or culture?) to matters of practices, doings, and actions" (Barad 2007, 135). This perspective shows that categorization - an apparatus of signification-plays a primary role in the active formulations of what matters and what is excluded from mattering.

These concepts can be applied to the history of the American oil industry. Industrial oil infrastructure, in its material-discursive ongoingness, is an apparatus. The exhibited artworks engage these concepts by enacting specific cuts together/apart with/in this apparatus but also enact conditions not readily legible in conventional industrial oil narratives. Oil actualizes (and excludes) such foundational ways of being in the world; deep excavation is needed to reanimate concepts that have concretized into natural conditions of life-such as that nylon stockings are produced for women's legs, that roads are for cars, or that oil is a fossil fuel for human use.

When did the concept of oil as a fossil fuel come into existence? In $1873 \mathrm{~J}$. T. Henry, one of the earliest authorities on the history of oil, referring to an 1833 paper in the "American Journal of Science" that describes a remarkable and terrible new spectacle of a river on fire, wrote:

Here we find Petroleum obtained more than thirty years before its final development, yet attended with all the accidents, and presenting all the phenomena that characterize its production in Pennsylvania. These are not accounts open to the suspicion of exaggeration. They were written and published more than a generation before the philosophy of Petroleum broke upon the understanding of man. (Henry 1873, 26)

What is the naturalized philosophy of petroleum that Henry speaks of? American oil industry historians mark the start of commercial drilling, at Drake Oil Well in 1859, as the transformation of a global network of fuel commodities. It occurs as Henry's philosophy of petroleum sets in and takes over the public imagination of development, of mechanization and automation, of the future. Conventional histories of the early American oil industry point to figures like Samuel Kier, who built the first oil refinery; George Bissell, founder of Seneca Oil, which built Drake Oil Well and was managed by Edwin Drake; J. L. Hutchings, who constructed the first oil pipeline; and others for recognizing and acting on the economic potential of this philosophy. But this history does not address the question: when did the concept of oil as a fossil fuel emerge? 
Carolyn Merchant's influential environmental history describes the origin of a Western, scientific vision of nature. Sir Francis Bacon's scientific education reforms at the beginning of the 1600s developed new ethics legitimizing the exploitation of nature and advanced an era in which "an organic conception of the cosmos gave way to a mechanistic model" (Merchant 1989, 42). Scientific education in the United States began at Yale University in the first decade of the 1800s, with Benjamin Silliman Sr., father of Silliman Jr., the first chemist to analyze crude oil for commercial purposes (at Yale). These educational programs were crucial steps in the new conceptualization of earth as historical and oil as a geologically created ancient carbon-based fuel, governed by the scientific-industrial perspective of nature as subordinate to "man." Despite the ongoing mutability of oil-and in part due to the sustained theological influence in science at the time-these programs advanced the basic inalienable assumption that oil is a fossil fuel with great power to animate industrial life.

To reimagine these anthropocentric histories as entangled naturecultures, practices for thinking oil require new methods, including thinking with oil. Others have proposed similar alternatives, such as Métis anthropologist Zoe Todd, who argues for reframing oil as kin (Todd 2017, 107). Indeed, Indigenous scholarship is one of the few fields taking seriously different oil ontologies. I propose that thinking with oil requires touching it, knowing it, and being with it in its various forms. The doing of this work engages unconventional modes of research and the double bind of (inter)disciplinary thinking-differentiating between art and science while diffractively thinking through them.

To this end, this essay shows and tells different possibilities of oil-in the way that Sarah Kember and Joanna Zylinska argue for media practice as critique (Kember and Zylinska 2012). In a broader context, the work aims for what science studies and critical race scholar Ruha Benjamin proposes: a third way of doing knowledge production that is not purely fact nor purely fiction because facts alone are not enough (Benjamin, n.d.). This practice brings attention to the specific medium of oil, but it also explores the medium's role in shaping its own practices of representation, oil's ongoing performativity. A brief history of oil reveals the vast possibilities of the substance and why such open-ended thinking is not only a speculative matter but also carries practical importance.

\section{Oil Mysticism: Oil Ontologies}

The series of artworks is a guide toward underexamined historical narratives of oil. The works reveal a fluid history of conceptualizing oil: what oil is has changed drastically over a relatively short period. Particularly, this series illuminates the unexpected link between industrialists and mystics during the early American oil industry. These strange bedfellows reveal a liveliness to oil that industrial capitalism has persistently attempted to render invisible, but which mystics present as spiritually enlightening. This mutual reverence for oil begins with the substance paraffin-one of numerous basic constituent 


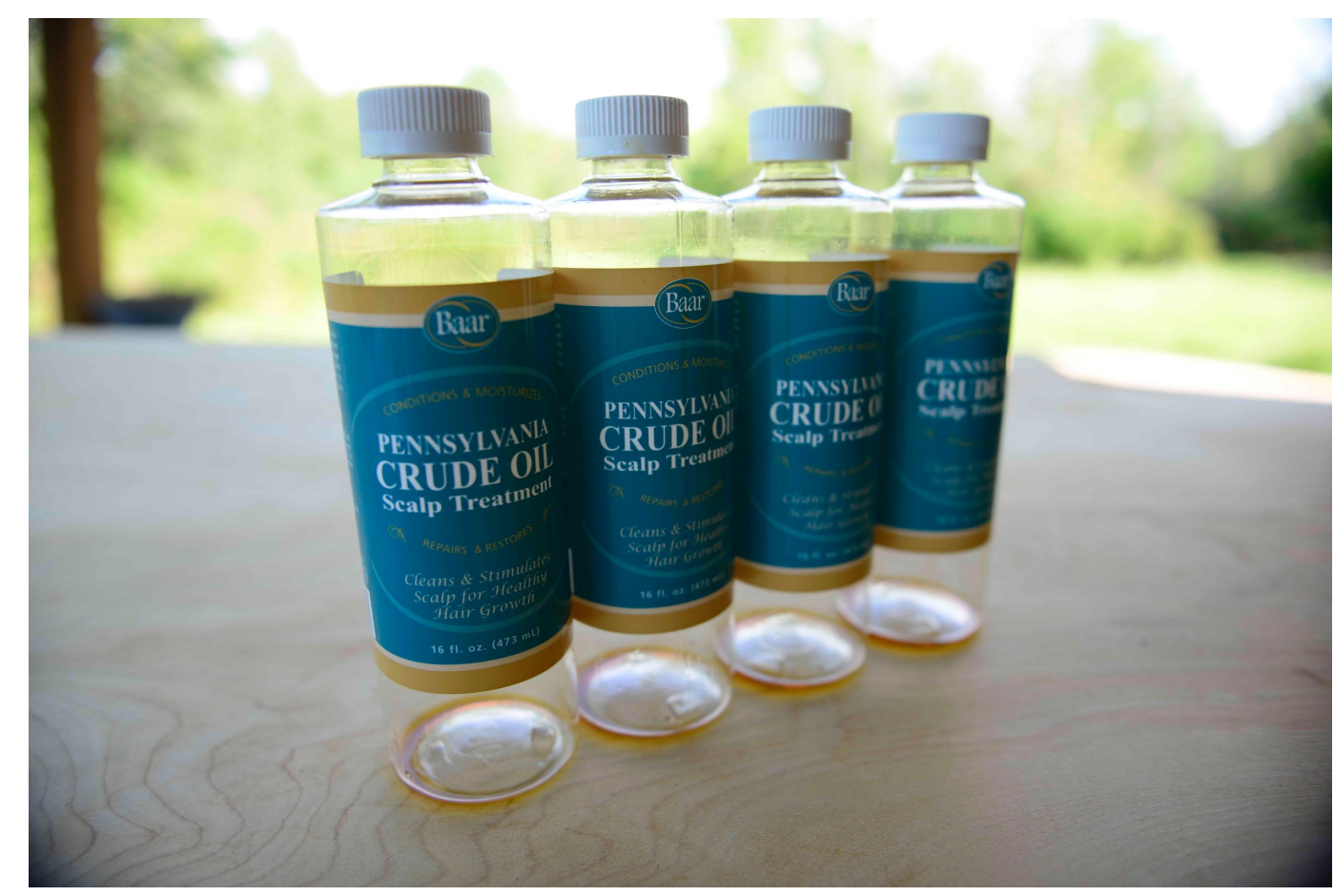

Figure 2: Four empty bottles of Crudoleum Pennsylvania Crude Oil Scalp Treatment, from Baar Products Inc. Photo: Elia Vargas.

hydrocarbons of oil. Paraffin is ubiquitous on earth, and the shared presence of hydrocarbons in human bodies and in oil fueled the arguments for these groups. Thomas Gold argued that for industrialists, this shared presence was proof of oil's environmental status, designating it ecologically safe to extract. Mystics revered the shared component in humans and oil as spiritually divine. Gold's argument was a fulcrum of Reza Negarestani's Cyclonopedia: Complicity with Anonymous Materials (Negarestani 2008). Cyclonopedia first prompted my search for a material source of crude oil.

It is easier to own crude oil as a commodity investment or to know its global index value than it is to hold it in your hands and feel its many viscosities. This fact is revealing of the way oil has been instrumentalized. The source that I could locate-on Amazon, after asking Google-is a small mom-andpop wellness company in Downingtown, Pennsylvania, called Baar Products Inc. They are the official resellers of a line of products called Cayce Care. Crudoleum is one such product (figure 2). The oil is sold in a BPA-free bottle. The product, based on Edgar Cayce's belief that paraffin is restorative, is evidence of the paraffin-based reverence for oil shared across industrial capitalism and historical American mysticism; the media art praxis, as will be shown, substantiated the research inquiry.

Alchemy and mysticism characterized oil long before it became a fossil fuel. Making oil fuel was a transformation that occurred over hundreds of years, reorienting the very idea of the ground underfoot. Oil Ontology: Genuine Earth Energy Manufactured by Elia Vargas is an edition of twelve 3D-printed (PLA 


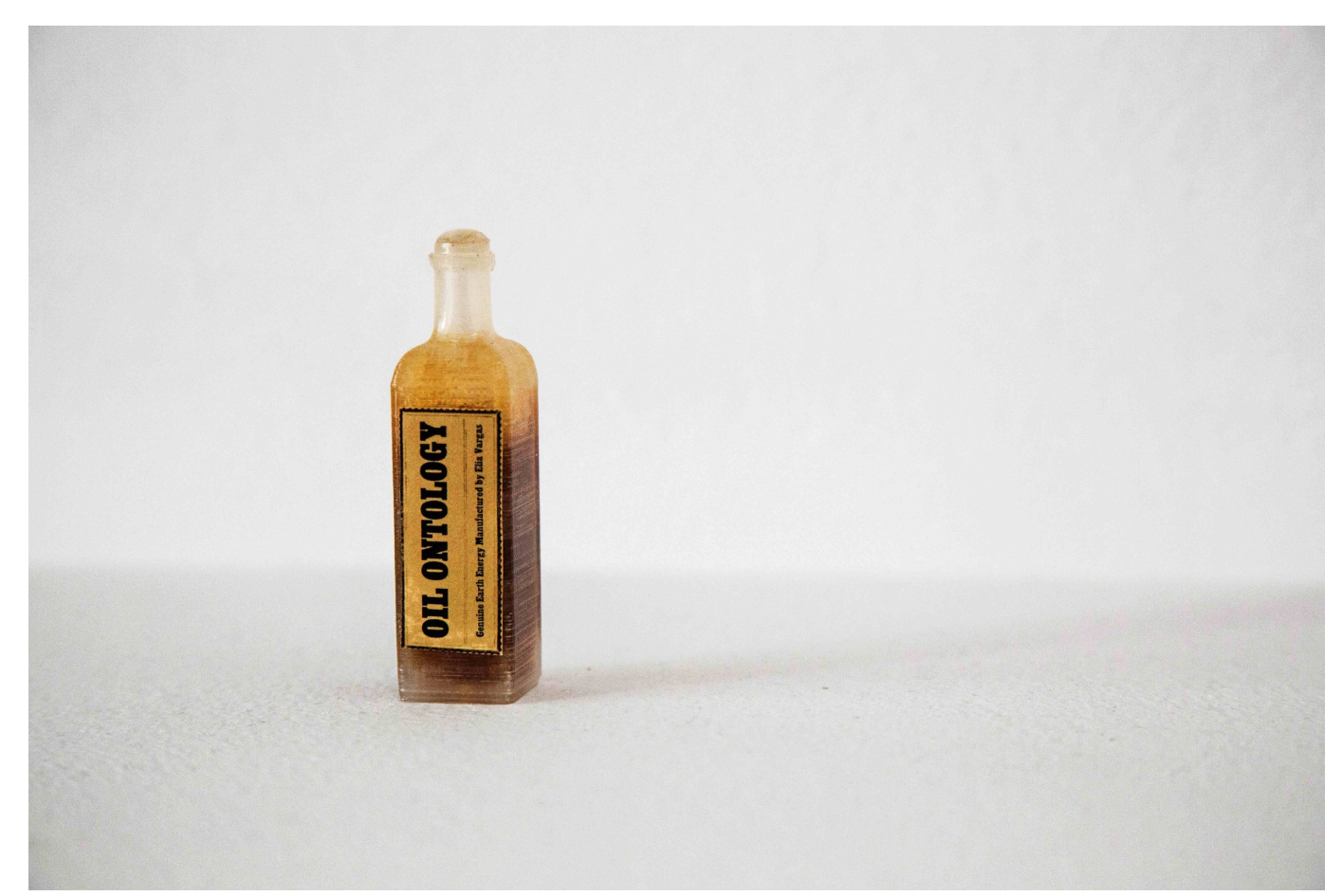

Figure 3: Oil Ontology: Genuine Earth Energy Manufactured by Elia Vargas.

Photo: Elia Vargas.

filament) crude oil medicinal bottles, sealed and containing Baar Inc. Crudoleum, 100\% Pennsylvania Crude Oil Scalp Treatment (figure 3). In conjunction with an oil hair-washing performance-talk, it was recently exhibited at Access Gallery's PLOT space in Vancouver, British Columbia, as part of the 2019 exhibition Under the Beating Sun, From Summer to Summer, organized by Far Afield, an artist-led initiative supported by the Canada Council for the Arts and British Columbia Arts Council. Curated by Caitlin Chaisson, the group exhibition explored "the relationship between sound and energy on a rapidly heating west coast through a consideration of two Summerlands: Summerland, British Columbia, and Summerland, California," and included talks with Stephanie LeMenager, Ursula Biemann, and others (Chaisson 2019). Oil Ontology embodies the material-discursive history of oil mysticism and oil medicine.

Crudoleum was invented by Edgar Cayce, a pioneer of American mysticism. Prior to commercial crude oil extraction, industrial salt miners once sold crude oil as a medicinal ointment. The history of medicinal crude oil far predates its use as a combustible energy source, and the replicated medicinal oil bottle, despite its uncanny appearance now, was once familiar. The additive construction technique of $3 \mathrm{D}$ printing the polymer oil bottles, building up a petrosubstrate-sealing off a history of medicinal petropractices via contemporary petroplastics - conceals historical alternatives to oil as fossil fuel. By presenting these literal, material, plastic limitations, which cut off access to the Crudoleum inside, Oil Ontology explores the ontological limit that 
industrial conceptions of crude oil have actualized in contemporary life. That is, Oil Ontology bottles up and restricts access to the historically common medicinal-in this case, hair-regenerative-conception of oil.

In the edited volume Petrocultures: Oil, Politics, Culture, Andrew Pendakis offers a compelling proposal: that oil is the ancient Greek arche, an origin or first cause, and that which renders change possible. "Oil is that upon which an enormous mass of extended, plastic Being directly relies for its beginning: it renders not just thinkable, but actualizable its very existence. There is an important double function here, at once epistemological and metaphysical: oil is simultaneously that through which the present becomes intelligible to itself and the very organizing principle or vital fluid by which it subsists" (Pendakis 2017). Oil Ontology takes this onto-epistemological position seriously and inverts it. The enormous mass of plastic Being has concretely-or rather via plastic resin-sealed off any competing oil potentialities.

Oil Ontology is a plastic artifact of the simultaneously erased medicinal history and the polymer infrastructure of the present. Since 1859 crude oil has been a fundamental building material of modern life. It replaced whale oil as the primary fuel for home illumination and accelerated a mass of new mechanization and plasticity. Its role in the US Civil War (as a lubricant) cannot be understated. It has not only become a correlation for economic value-a global commodity - but also has transformed the very way things are made and get done. Oil medicine and mysticism are an underexamined part of this history. The hydrocarbon paraffin, discovered in 1830 by German chemist Karl von Reichenbach, is a major agent of this reexamined genealogy. Critical infrastructuralist Keller Easterling's concept of disposition is a generative way to consider paraffin (Easterling 2010); as she writes, "Disposition, as the unfolding relationship between potentials, resists science and codification in favor of art or practice.”

The disposition of paraffin is highly dynamic. It coagulates in a way that clogs pipelines, determined by the cloud point measurement of paraffin wax buildup; this can be considered a form of material self-sabotage. It is an ecological limit on the flow of commodification, which I take on in the 2016 installation Cloud Point (figure 4), influenced by media theorist Darin Barney (Barney 2013). Paraffin also burns, melts at a certain temperature, and remains solid at another. Paraffin is present in numerous different plant and animal species, and it can be synthesized and sold. Chemistry defines paraffin as "straight-chain or branched saturated organic compounds with the composition $\mathrm{C}_{\mathrm{n}} \mathrm{H}_{2 \mathrm{n}+2}$ ” (Freund 1982, 11). As a common hydrocarbon across life forms, its indexed chemical structure grants it a certain ubiquitous status on earth. The synthesis of kerosene in the 1850 s is one of many important dispositions of paraffin. As the domestication of light persisted through the latter part of the 1800s, paraffin co-constituted conditions for existence: 


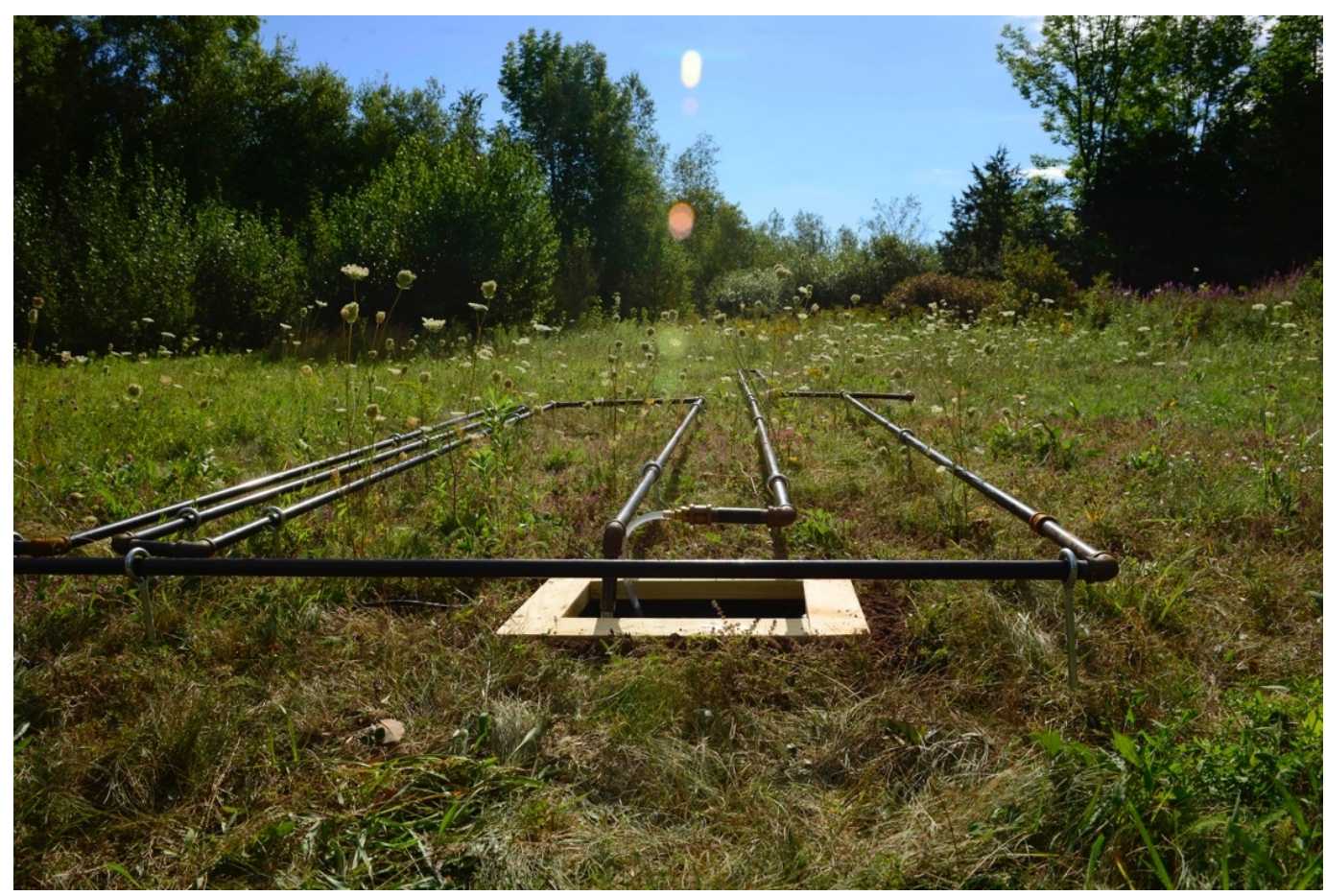

Figure 4: Cloud Point: A Derivative of Crude Illumination by Elia Vargas, a crude oil pipeline and sonic feedback installation, created and exhibited at Wave Farm Transmission Arts, Acra, New York, 2016.

Photo: Elia Vargas.

reducing the toxicity of interior living spaces; introducing mechanisms for controlling artificial light quality; mobilizing changing domestic practices in the home; and amplifying altogether new social practices.

The etymology of the word petroleum dates back more than a thousand years, and, as Grantley McDonald has shown, before kerosene and the detection of paraffin, oil was primarily documented for its use in medicine. "Agrícola did not coin the Latin word petroleum; this honour should go rather to Constantinus Africanus (c. 1020-1087). Rather, Agrícola drew upon a rich tradition of employing petroleum in medicine, a tradition familiar to him through his professional training as a doctor" (McDonald 2011, 363). Many medicinal products, new and very old, derive from oil, as do many resulting mystical practices. Karl von Reichenbach devoted the later years of his life to the search for a vital substance he named "Od," Old German for "all permeating” (Nahm 2011). Although Reichenbach discovered paraffin in 1830, tenth-century Persian alchemist Abu Bakr Muhammad ibn Zakariya alRazi provides the first written account of using petroleum as an illumination source in The Book of Secrets (Taylor 2015).

Edgar Cayce was an oil-mystic newcomer when he imagined Crudoleum during a trance state. He said that "sweet crude" has the ability to stimulate hair growth because it is rich in paraffin (Cayce 1935). During a reading at the Warshawsky home in Detroit, Michigan, on November 18, 1935, he prescribed crude oil as a medicinal scalp treatment for hair loss: 
8. (Q) What causes the falling out of the hair, and what should be done to prevent it? (A) This is a lack of an activity through the glands that are secreting from the system the elements necessary to make for activity in those portions of the thyroids... Those portions where this is indicated would be stimulated by a massage - which may be had with properties that aid the scalp circulation; such as a small quantity of the crude Oil.... (Cayce 1935)

During the years 1918-20, Cayce started his own oil prospecting company, Cayce Petroleum Inc., to divine the location of oil wells and use the profits to fund his teaching institute. Many oil prospectors had already requested psychic readings by Cayce to aid in locating wells, a common practice at the time.

Before Cayce, numerous medicinal oil practices existed at the time of Drake Oil Well in Titusville, Pennsylvania. It is common knowledge among oil historians that the Seneca tribe used crude oil pits for healing baths (Brice 2009). Oil soaking was known throughout the world, dating back a thousand years, largely due to the medicinal naphthalan oil baths of Naftalan City, Azerbaijan. The industrialized version of medicinal oil was tapped by Kier, known all too fondly as the grandfather of the American oil industry, in Pittsburgh in the 1840s. Kier's wife, or his friend's wife-historical accounts are vague, but the paternalistic tone is consistent-was prescribed crude oil as a topical medicine, and Kier determined it was the same material contaminating his salt brine (figure 5). The early oil industry was rampant with similar inexact, nonscientific, nonrationalist, myth-laden dreams of oil riches, despite oil's indoctrination with/in industrialization. It is not that non-Western, nonscientific perceptions of oil were inferior, but rather that the new conception of oil (Henry's philosophy of petroleum) masqueraded as the cradle of rationalist, objective, scientific knowledge.

\section{Climate Change in the Gallery Space}

By thinking with oil in hands-on, experimental, research- and art-based ways, we can expand beyond industrial representation of it. In their place, oil can be understood as a dynamic material-discursive substance without representational characteristics of fossil fuel prior to the forces that (re)presented it as fossil fuel. As Barad puts it, "the point is not merely that knowledge practices have material consequences but that practices of knowing are specific material engagements that participate in (re)configuring the world" (Barad 2007, 91). Instead of an agent of human productivity, crude oil is the spacetimemattering of solar light and biomass of the deep earth (Barad 2007, 179).

Crude Illumination (2015), most recently exhibited in Thekla (2018), a group show curated by Lauren Marie Taylor at Southern Exposure Gallery, San Francisco, was the first light installation I made using crude oil (figure 6). By creating the conditions for an obsolete media apparatus to materialize specific 


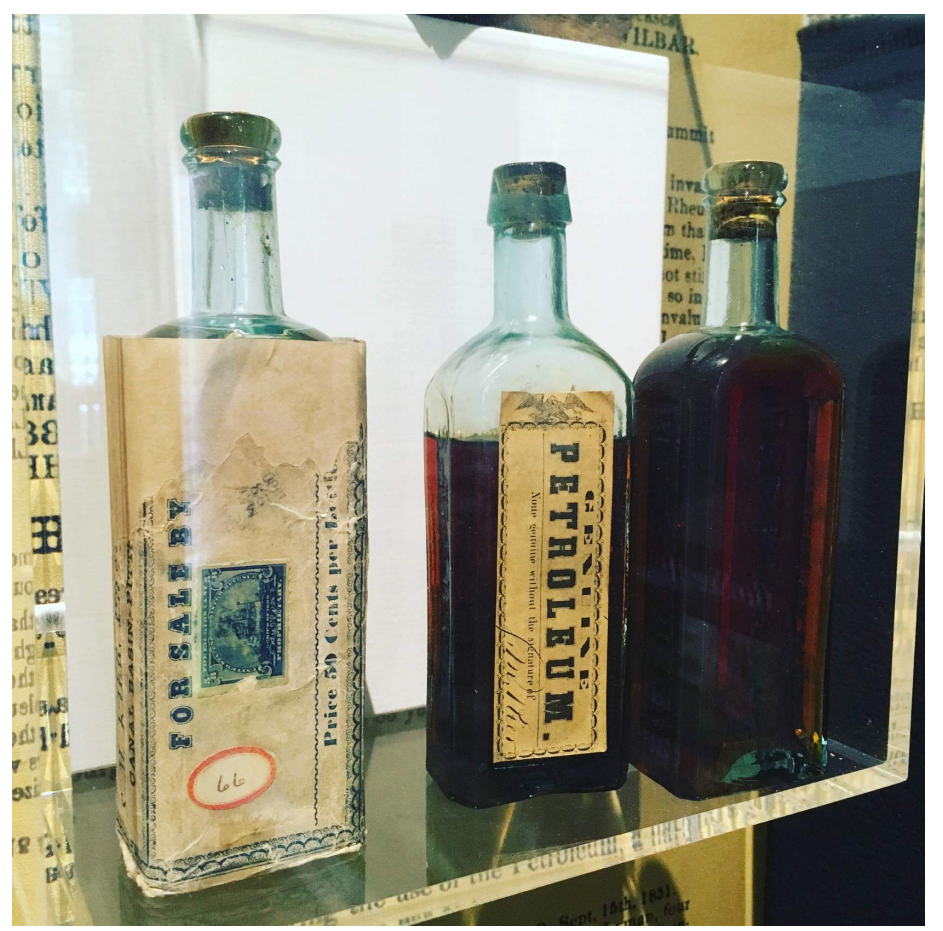

Figure 5: Historical bottle of Kier Petroleum Medicinal Ointment at Drake Oil Well Museum, Titusville, Pennsylvania. Photo: Elia Vargas.

dispositions of crude oil, the work focuses on an elemental conception of transmission and inscription while illuminating the media archaeology of certain light apparatuses. Crude Illumination is a crude oil, light projection installation; it features an analog overhead projector that visually enlarges an acrylic container filled with crude oil and dry ice. Dry ice is frozen carbon dioxide, and it sublimates from a solid to a gas at $-109.3^{\circ} \mathrm{F}$. As the overhead projector illuminates the glacial change of the oil and the dry ice, carbon dioxide slowly sublimates into the atmosphere, thereby enacting climate change in the gallery space.

The overhead projector is not incidental in this ongoing materialization of oil and light; it is also a specific apparatus of differentiation. Mining the history of the overhead projector reveals an unsurprising link to the military-industrial complex. There are no clear histories of the overhead projector, a task in need of further media scholarship, but some sources point to its early development by French optical scientist Jules Duboscq in the 1880s (Gansing 2013). It has been suggested that it was first used as a tool for police departments to enlarge criminal fingerprint records. While it is difficult to substantiate this suggestion, the overhead projector came into common use standardizing and modernizing World War II training procedures. The specific conditions that enact the apparatus-as a material-discursive arrangement-matter.

Crude Illumination is a light projection installation-not a projection on a surface but an entire arrangement. The room, the atmosphere, the open space to move about, the light, the oil, the elemental and the technological materials, 


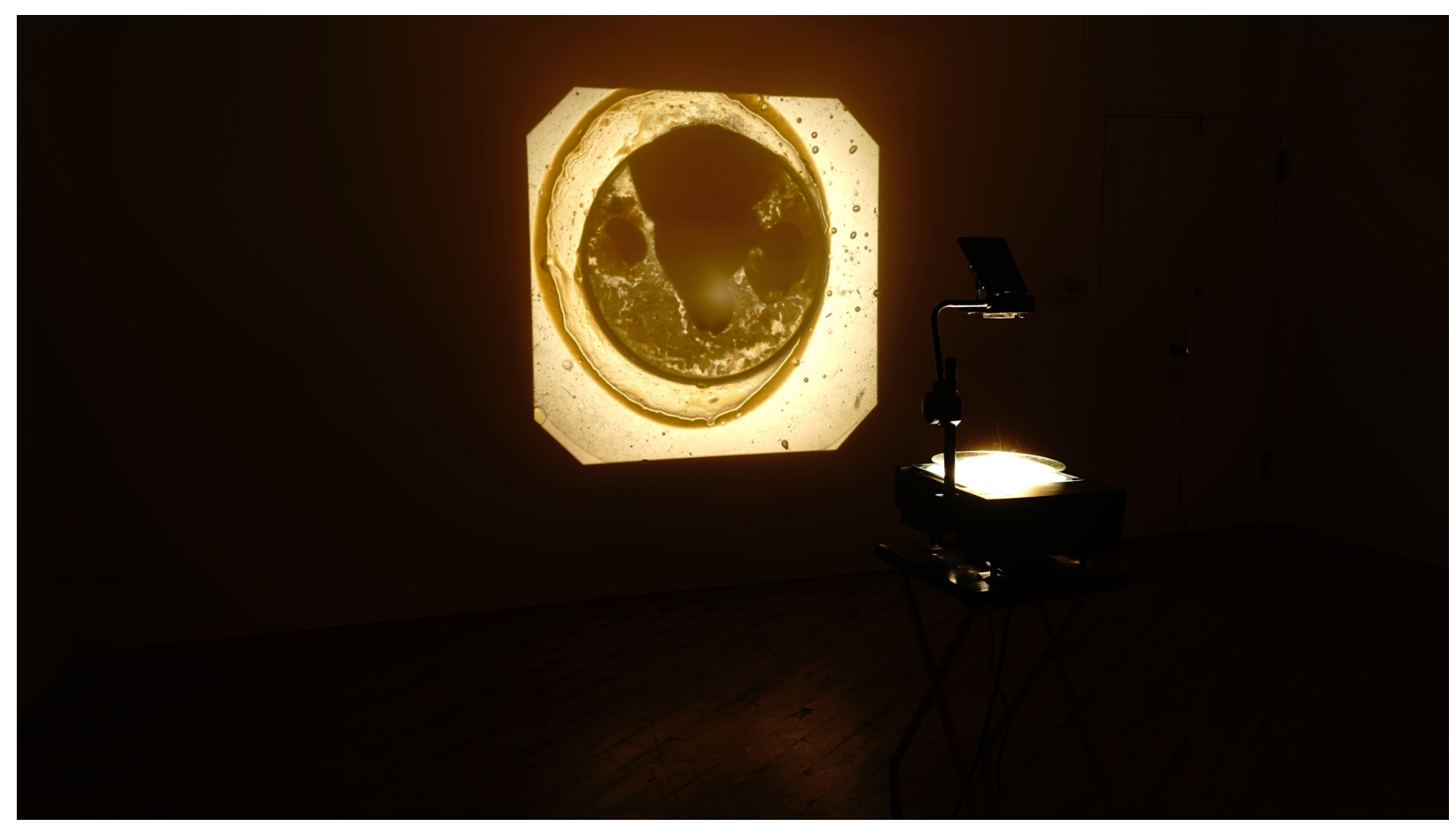

Figure 6: Studio installation view of Crude Illumination (2015) for ISEA2016 Hong Kong Artist Talk.

Photo: Elia Vargas.

all matter. The installation enables a deep looking at the materialization of hydrocarbon transformation: it is a plurality of metaphors and materials. It resembles oily seepage contaminating Arctic glacial shelves, evoking representations of climate change, and it probes a history of analog technology. It is attentive to the role the overhead projector plays in illuminating the conditions of the work-in fact, the conditions of illumination are the materializing force of the work. But, most importantly, the installation creates actual, physical, light-oil carbon transformation in the gallery (figure 7). The disposition of these mediums (oil, frozen carbon dioxide, light, and the light projection hardware), in their intra-active metamorphosis, is the work. While it produces a visual representation, it is most notably an ongoing materialdiscursive becoming.

Crude Illumination was a response to a series of experiments on light and water as elemental information and transmission. Light, in its optical media conception, is a carrier wave of information. In its projected form, it is also a material marking a surface (a wall projection, for example). I sought to identify some of the entanglements of the naturecultural context of light projection. It is an interesting state where different forms of information are revealed or excluded based on the technosocial semiotic understanding of what projection is: a series of symbols on a wall projected from a light-emitting device. But this comprehension of light ignores the fact that the electromagnetic spectrum exists in a range that exceeds human legibility and has material impacts that are not representational. Crude oil proved to be a more contested earth substance in this exploration because human-oil histories have always been tethered to 


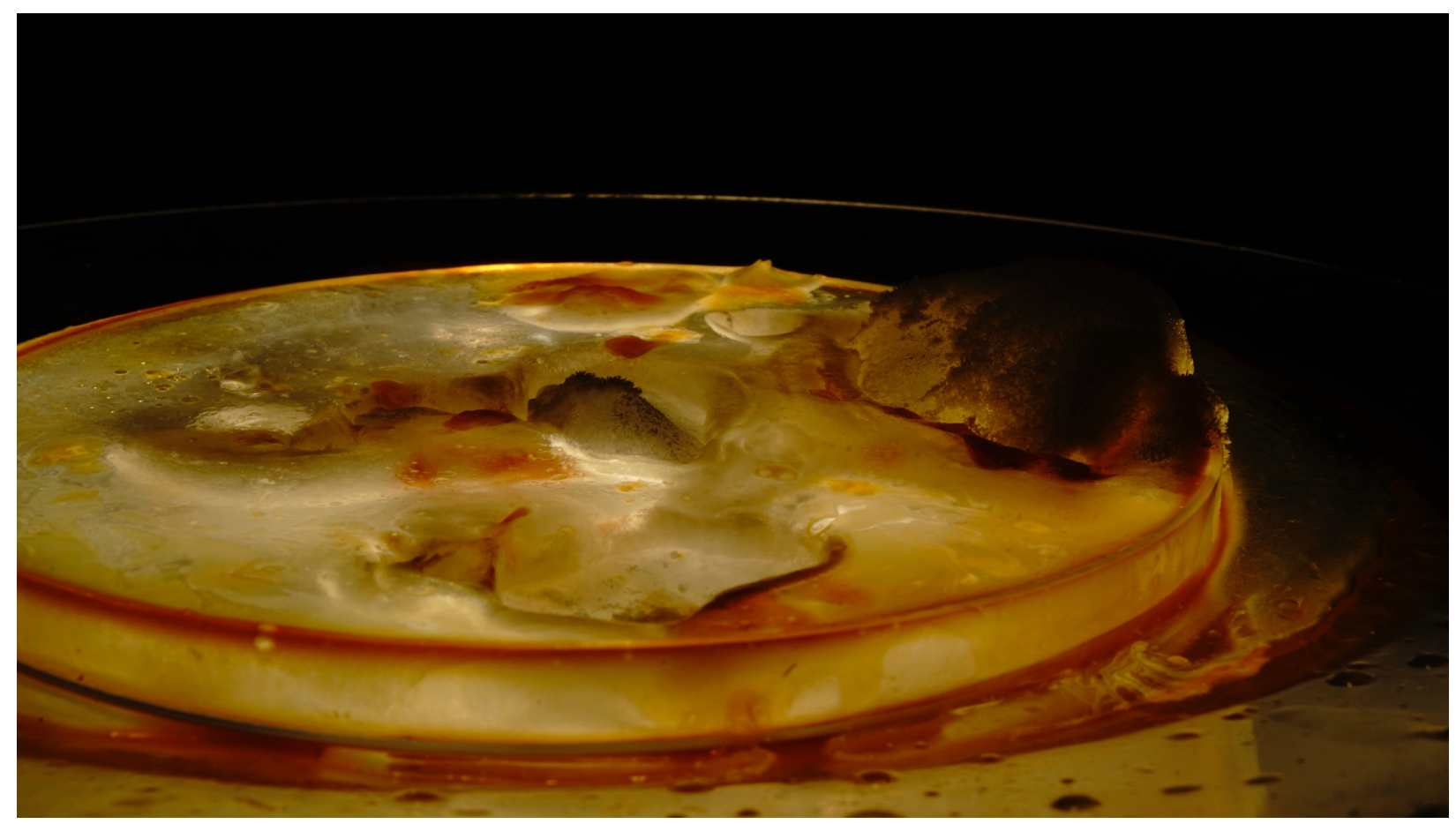

Figure 7: Detail of oil sublimating frozen carbon dioxide, Crude Illumination.

Photo: Elia Vargas.

light (the biblical eternal flames of naphtha, kerosene, a replacement for whale oil, etc.). But more importantly, from a posthumanist perspective, thinking about oil means thinking about the sun.

Linking the material inscription of projection light to oil as solar inscription of the earth troubles conventional media materialism. Elemental media theorist John Durham Peters suggests, "[once] communication is understood not only as sending messages-certainly an essential function-but also as providing conditions for existence, media cease to be only studios and stations, messages and channels, and become infrastructures and forms of life" (Peters 2015, 265). Thinking about oil and the sun opens different temporalities, beyond conceptions of humanist media. Thinking about oil and the sun opens thinking about the potential of oil in numerous nonabstract ways: how does solar radiation become oil underneath the ground, and what does that mean for the metaphors that suggest oil is the sludge of the earth? What is the spacetime of oil? How do Western industrial human representations of oil map onto that?

In fact, chemists say oil is one of the most bio-rich materials that humans have ever found. Thus, it gets used for many different purposes; this is why mystics and industrialists were so infatuated with it. It can $d o$ so many different things; what it does-its disposition - is part of the process of how it becomes normalized. How the concept of oil is formed, through its disposition, is vitally important. This perspective echoes Scott's critique of the fossil-fueled 
ontology. Thinking about oil-sun relations means thinking oil in relation to life in its becoming. In physically doing different things with oil, I aim to expand the conception of what oil is.

\section{Oil Rituals for the Future: Distilling Bodies and Energies}

The mutable disposition of oil has offered grand visions of the future since the earliest days of its commodification. Benjamin Silliman Jr.'s fractional distillation of crude oil in 1854 was the first chemical analysis of oil for commercial purposes. Bissell and J. G. Eveleth, founders of the Seneca Oil Company, brought a sample of oil from their new land, Hibbard Farm, in Titusville, Pennsylvania, to Silliman Jr., chair of the Yale University Chemistry Department (Brice 2009, 143). Silliman Jr.'s analysis, Report on the Rock Oil, or Petroleum, from Venango Co., Pennsylvania: With Special Reference to Its Use for Illumination and Other Purposes, transformed the future of oil. His report offered three transformative assessments of oil:

1. Silliman concluded that the entire petroleum product could be monetized. "It is worthy of note," he wrote, "that my experiments prove that nearly the whole of the raw product may be manufactured without waste [...] by a well directed process which is in practice, one of the most simple of all chemical processes” (Silliman 1855, 20).

2. Silliman determined that crude oil is indeed a productive, if not highly efficient, means of illumination: "It produced nearly pure carbureted Hydrogen Gas, the most highly illuminating of all the carbon gases” (Silliman 1855, 11).

3. Silliman unknowingly foreshadowed the invention of synthetic petrochemicals and polymers, such as plastics and nylon: "The uncertainty of the boiling points indicates that the products obtained at the temperatures named above, were still mixtures of others, and the question forces itself upon us, whether these several oils are to be regarded as educts, (i.e, bodies previously existing, and simply operated in the process of distillation,) or whether they are not rather produced by the heat and chemical change in the process of distillation [sic]. The continued application of an elevated temperature alone is sufficient to effect changes in the constitution of many organic products, evolving new bodies not before existing in the original substance” (Silliman 1855, 9).

The first synthetic material, nylon (subsequently used in the production of women's stockings), was indeed a product of oil synthesis, orchestrated by the DuPont Company on February 28, 1935. In 2018 curator Ceci Moss invited me to exhibit new work in the exhibition Anatomy of Oil, in the Los Angeles gallery Gas (figure 8). Provocative in its own right, Gas is a mobile 


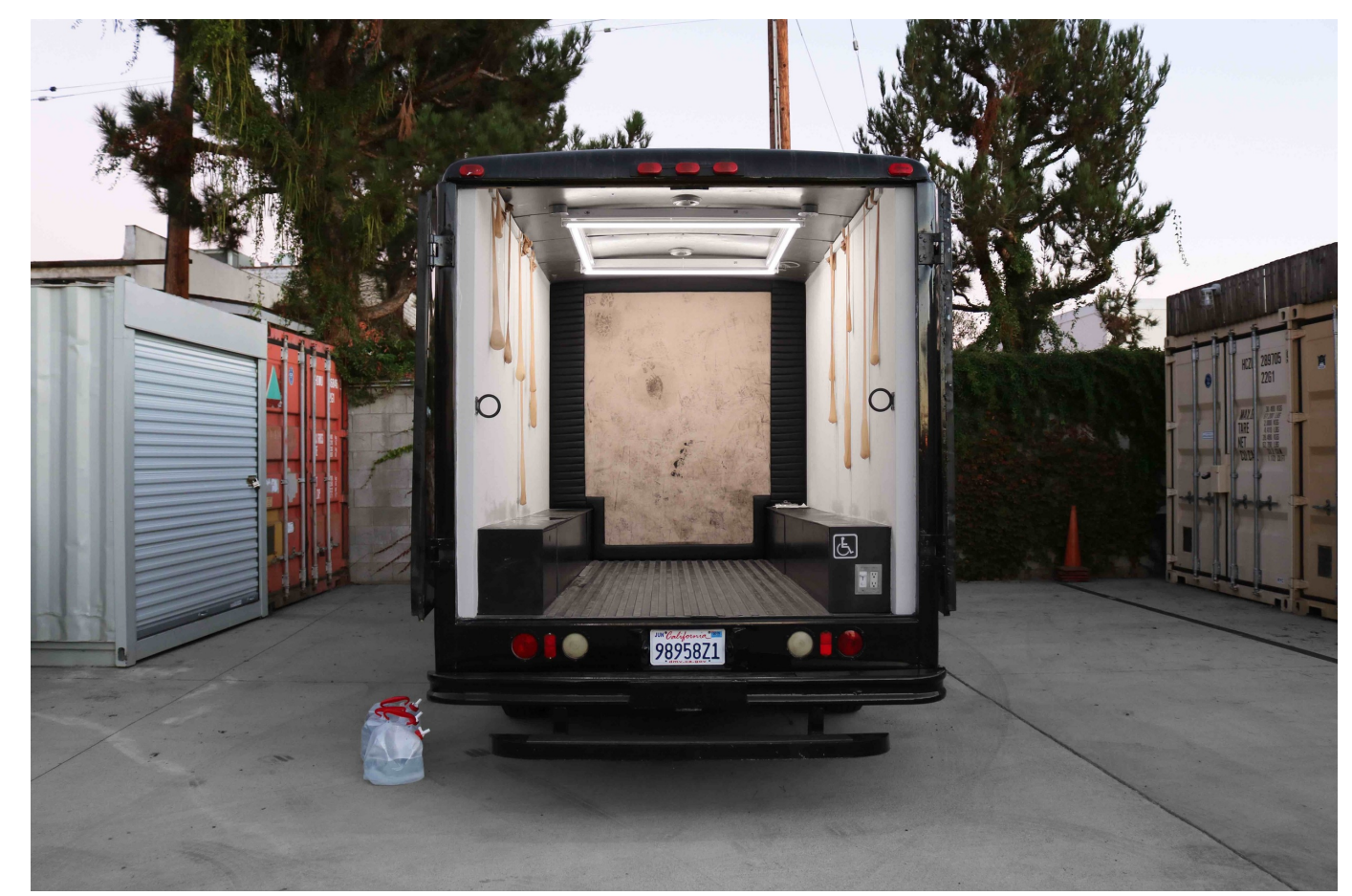

Figure 8: Anatomy of Oil exhibition, Gas Gallery, showing Oil rituals for the future \#6 (2018).

Photo: Andy Bennett and Colleen Hargaden. Reproduced with permission.

gallery built from a repurposed delivery truck, which geographically situates itself in relationship to the work it exhibits. For this new work, I explored the mutability of oil in its very real impact on gendering bodies.

Anatomy of Oil constructed a dialogue with the hidden presence of oil across the Los Angeles landscape. In Moss's words:

Named after a poem by Marcella Durand that examines these issues through an eco-feminist lens, Anatomy of Oil includes sculpture, drawing, painting, and video in the gallery truck... One theme in Durand's poem is a ceaseless, roaming hunger for oil, and the destructive path that follows each discovery...

Works such as Elia Vargas's sculpture [figure 9] Oil rituals for the future \#6 (2018) attend to the material qualities of oil itself, and how they formally contribute to its pervasiveness both economically and culturally. The work is made of paraffin wax, a hydrocarbon derived from petroleum. Paraffin wax was discovered in 1830, transforming home illumination, and it continues to be used in food, beauty products, and manufacturing. Contained in nylon stockings [figure 10] (the first synthetic material, derived from petroleum in a DuPont research lab in 1935), the sculptures are designed to melt in concert with the heat conditions of the truck gallery. This slow 


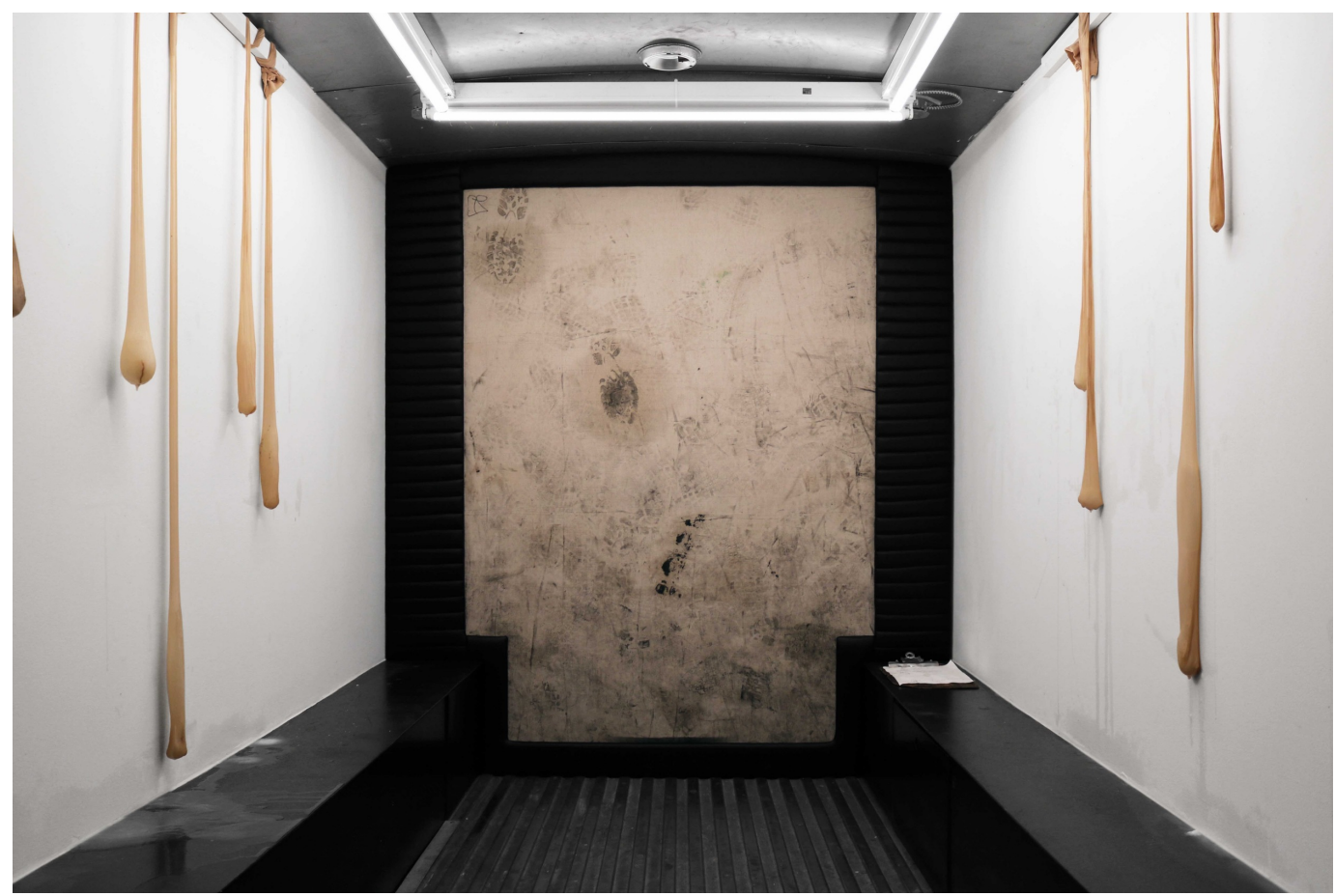

Figure 9: Oil rituals for the future \#6 installation view.

Photo: Andy Bennett and Colleen Hargaden. Reproduced with permission.

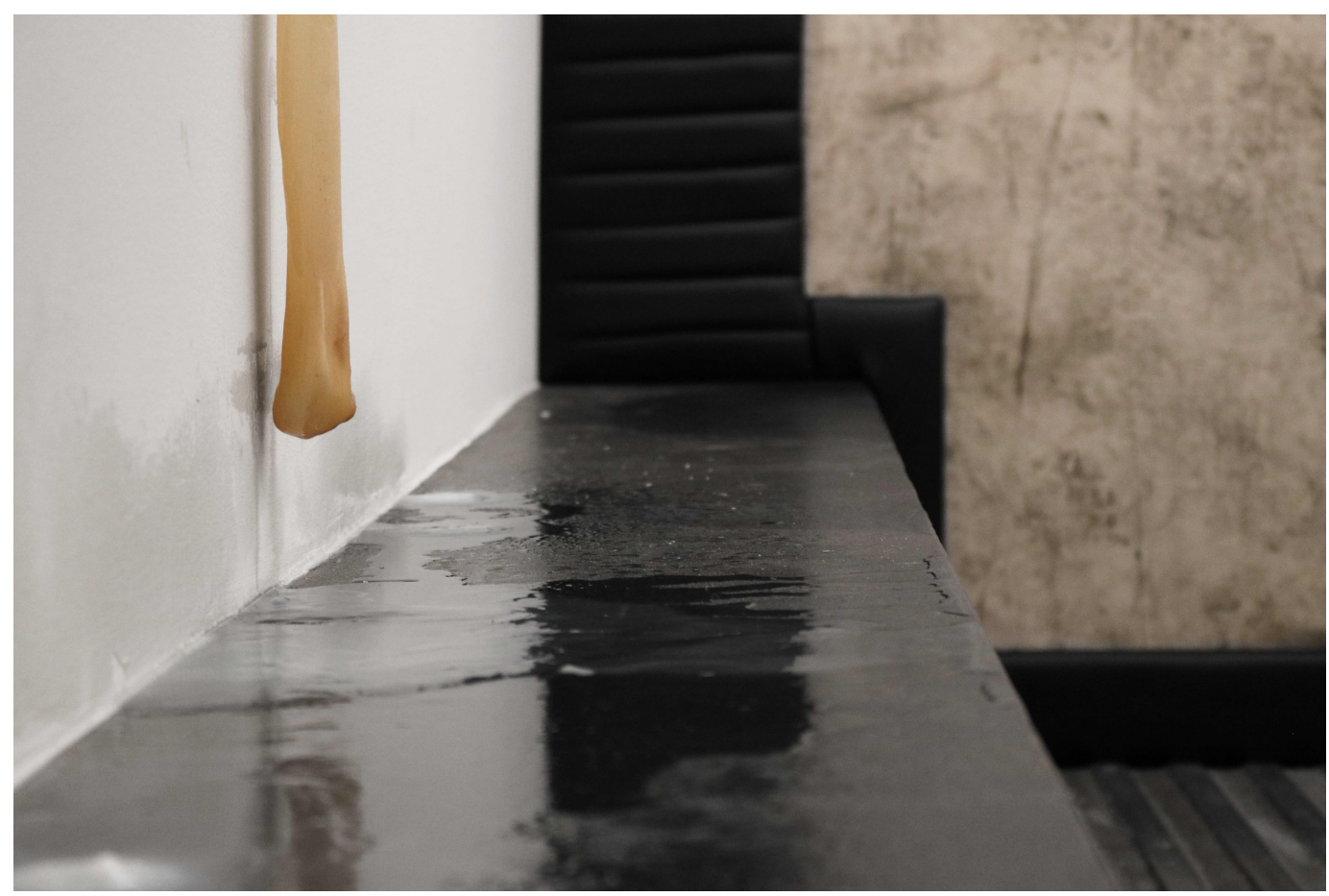

Figure 10: Detail of paraffin wax melting in Oil rituals for the future \#6.

Photo: Andy Bennett and Colleen Hargaden. Reproduced with permission.

and unpredictable transformation mirrors oil's mutability and relentless impact on the cultural formation of the body. (Moss 2018) 
Relentless to be sure, industrial era practices of gender are not free of the ongoing materialization of oil. DuPont intentionally did not patent nylon to allow its pervasive normalization (e.g., molding women's legs) throughout American society. Oil rituals for the future \#6, an expanding series, sought to focus on this ongoing mutability by showing the state change of paraffin in sync with the very conditions of the exhibition: where it went, the ambient temperature, the ignition of the engine, and the presence of visitors. The ongoing materialization of paraffin-as nylon, as kerosene, as medicine-reveals the mutability of oil. The enormous mass of extended plastic Being, which Pendakis speaks of, emerges simultaneously with and through petro-subjectivity, as intra-active agents, every time new nylon progeny take form, as bodies, as concepts, as life.

\section{Conclusion}

Why refigure oil as media? In the simplest of terms, oil is too often understood as a binary. It is represented either as an unavoidable industrial catalyst carrying the potential for great energy and wealth, or as a catastrophic environmental hazard responsible for vast ecological destruction. Agential realism shows that oil is not a raw material defined solely by the Western industrial representations that govern it today. Conceptualizing oil as media provides new modes to unearth the ongoing differentiation of oil. To examine this, I have turned toward a media art practice that materializes ongoing differentiations of oil: plastic 3D-printed medicinal bottles, climate change in the gallery space, nylon, and paraffin. This is just the beginning of a much broader reconfiguring of oil and/as media.

With/in the artworks, I have aimed to diffractively address ontological, epistemological, and ethical considerations of the industrial conception of oil as fossil fuel. Why is the status of oil as an inert material, accessible for active human agents to exploit and extract, not more seriously critiqued? Oil is enacted as a relation between earth and sun. Working with the tensions between American mysticism and the early American oil industry, Oil Ontology, Crude Illumination, and Oil rituals for the future \#6 highlight the not so straightforward naturecultural relationships of oil. These practices of making both reciprocally determine and blur with my practices of thinking. Refiguring oil mobilizes alternative practices for new conceptions of a substance that resists categorization, precisely because it is everywhere. 


\section{REFERENCES}

Barad, Karen Michelle. 2007. Meeting the Universe Halfway: Quantum Physics and the Entanglement of Matter and Meaning. Durham, NC: Duke University Press. https://doi.org/10.1515/ 9780822388128.

Barney, Darin. 2013. "Sabotage and the Politics of Pipelines." Presented at the Institute for the Humanities, Simon Fraser University, Vancouver, BC, October 4. https://www.youtube.com/ watch?v=UjJO5 fiMGU.

Benjamin, Ruha. n.d. “Reimagining Science and Technology.” AAS 21. https://aas.princeton.edu/ news/aas21-podcast-episode-12-reimagining-science-and-technology.

Bloom, Brett. 2015. Petro-Subjectivity: De-Industrializing Our Sense of Self. Ft. Wayne, IN: Breakdown Break Down Press.

Bowker, Geoffrey C. 1994. Science on the Run: Information Management and Industrial Geophysics at Schlumberger, 1920-1940. Inside Technology. Cambridge, Mass.: MIT Press.

Brice, William R. 2009. Myth, Legend, Reality - Edwin L. Drake and the Early Oil Industry. 1st ed. Oil City, PA: Oil Region Alliance.

Cayce, Edgar. 1935. “A.R.E TEXT OF READING 480-23 F 23.” Edgar Cayce’s Association for Research and Enlightenment.

Chaisson, Caitlin. 2019. “Summerland.” Far Afield. 2019. https://www.farafield.ca/summerland.

Daggett, Cara New. 2019. The Birth of Energy. Durham, NC: Duke University Press.

Easterling, Keller. 2010. “Disposition.” In Cognitive Architecture: From Biopolitics to Noopolitics, edited by Deborah Hauptmann and Warren Neidich. Rotterdam: 010 Publishers. http://kellereasterling.com/articles/disposition.

Freund, Mihály. 1982. Paraffin Products: Properties, Technologies, Applications. Elsevier Scientific Publishing Company.

Gansing, Kristoffer. 2013. "Transversal Media Practices: Media Archaeology, Art and Technological Development.” Doctoral Thesis, Faculty of Culture and Society, Malmö University.

Haraway, Donna Jeanne. 2003. The Companion Species Manifesto: Dogs, People, and Significant Otherness. Chicago: Prickly Paradigm Press.

Henry, J.T. 1873. The Early and Later History of Petroleum, with Authentic Facts in Regard to Its Development in Western Pennsylvania... Also Life Sketches of Pioneer and Prominent Operators... Philadelphia: Jas. B. Rodgers Co.

Huber, Matthew T. 2013. Lifeblood: Oil, Freedom, and the Forces of Capital. Quadrant Book. Minneapolis: University of Minnesota Press. https://doi.org/10.5749/minnesota/ 9780816677849.001 .0001$.

Kember, Sarah, and Joanna Zylinska. 2012. Life after New Media: Mediation as a Vital Process. Cambridge, MA: MIT Press. https://doi.org/10.7551/mitpress/8796.001.0001.

LeMenager, Stephanie. 2014. Living Oil: Petroleum Culture in the American Century. Oxford University Press. https://doi.org/10.1093/acprof:oso/9780199899425.001.0001.

Malm, Andreas. 2016. Fossil Capital: The Rise of Steam Power and the Roots of Global Warming. London: Verso.

McDonald, Grantley. 2011. "Georgius Agrícola and the Invention of Petroleum.” Bibliothèque d'Humanisme et Renaissance 73 (2): 351-64.

Merchant, Carolyn. 1989. The Death of Nature: Women, Ecology, and the Scientific Revolution. New York: Harper \& Row. 
Mitchell, Timothy. 2011. Carbon Democracy: Political Power in the Age of Oil. London; New York: Verso Books.

Moss, Ceci. 2018. “Anatomy of Oil - Gas.” 2018. https://gas.gallery/exhibitions/anatomy-of-oil/.

Nahm, Michael. 2011. "The Sorcerer of Cobenzl and His Legacy: The Life of Baron Karl Ludwig von Reichenbach, His Work and Its Aftermath.” Journal of Scientific Exploration 26: 381-407.

Negarestani, Reza. 2008. Cyclonopedia: Complicity with Anonymous Materials. re.Press.

Parikka, Jussi. 2009. “Apparatus Theory of Media á La (or in the Wake of) Karen Barad.” Machinology (blog). July 16, 2009. https://jussiparikka.net/2009/07/16/apparatus-theory-of-media-a-la-or-inthe-wake-of-karen-barad/.

- - 2015. A Geology of Media. Minneapolis; London: University of Minnesota Press. https://doi.org/10.5749/minnesota/9780816695515.001.0001.

Pendakis, Andrew. 2017. “Being and Oil: Or, How to Run a Pipeline through Heidegger.” In Petrocultures: Oil, Politics, Culture, 377-88. McGill-Queen's University Press. http://www.jstor.org/stable/j.ctt1qft0q7.24.

Peters, John Durham. 2015. The Marvelous Clouds: Towards a Philosophy of Elemental Media. Chicago: University of Chicago Press. https://doi.org/10.7208/chicago/9780226253978.001.0001.

Pinkus, Karen. 2016. Fuel: A Speculative Dictionary. Minneapolis: University of Minnesota Press. Scott, Heidi C.M. 2018. Fuel: An Ecocritical History. London: Bloomsbury.

Silliman, Benjamin. 1855. Report on the Rock Oil, or Petroleum, from Venango Co., Pennsylvania: With Special Reference to Its Use for Illumination and Other Purposes. New Haven: From J.H. Benham's steam power press.

Taylor, Gail Marlow. 2015. The Alchemy of Al-Razi: A Translation of the "Book of Secrets". 1st ed. CreateSpace Independent Publishing Platform.

Todd, Zoe. 2017. "Fish, Kin and Hope: Tending to Water Violations in Amiskwaciwâskahikan and Treaty Six Territory." Afterall: A Journal of Art, Context and Enquiry 43 (March): 102-7. 